\title{
Estimated average glucose
}

National Diabetes Information Clearinghouse (NDIC)

\section{Definitions}

Glucose

Defined by National Diabetes Information Clearinghouse (NDIC)

$\mathrm{mg} / \mathrm{dL}$

Defined by National Diabetes Information Clearinghouse (NDIC)

\section{Blood glucose meter}

Defined by National Diabetes Information Clearinghouse (NDIC)

A1C

Defined by National Diabetes Information Clearinghouse (NDIC)

\section{Source}

National Diabetes Information Clearinghouse (U.S.). (2009). The diabetes dictionary. [Bethesda, Md.]: U.S. Dept. of Health and Human Services, National Institutes of Health, National Institute of Diabetes and Digestive and Kidney Diseases, National Diabetes Information Clearinghouse.

Also called $\mathbf{e} A G$ or average glucose; another way to report the results of an $A 1 C$ test. The $A 1 C$ test measures average glucose levels over the past 2 to 3 months. In the past, results were reported as a percentage. Results reported as an eAG are given as $m g / d L$, the same units used for self-monitoring of blood glucose with a blood glucose meter. For example, results of an $\mathrm{A} 1 \mathrm{C}$ test can be reported as an eAG of $126 \mathrm{mg} / \mathrm{dL}$, which is equal to 6 percent. 